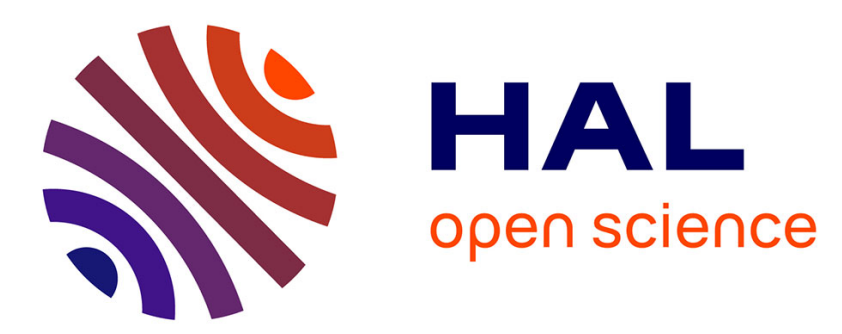

\title{
In-situ experimental and numerical studies of the damage evolution and fracture in a Fe-TiB2 composite
}

Zehoua Hadjem-Hamouche, Katell Derrien, Eva Héripré, Jean-Pierre Chevalier

\section{To cite this version:}

Zehoua Hadjem-Hamouche, Katell Derrien, Eva Héripré, Jean-Pierre Chevalier. In-situ experimental and numerical studies of the damage evolution and fracture in a Fe-TiB2 composite. Materials Science and Engineering: A, 2018, 724, pp.594-605. 10.1016/j.msea.2018.03.108 . hal-01825611

\section{HAL Id: hal-01825611 \\ https://hal.science/hal-01825611}

Submitted on 28 Jun 2018

HAL is a multi-disciplinary open access archive for the deposit and dissemination of scientific research documents, whether they are published or not. The documents may come from teaching and research institutions in France or abroad, or from public or private research centers.
L'archive ouverte pluridisciplinaire HAL, est destinée au dépôt et à la diffusion de documents scientifiques de niveau recherche, publiés ou non, émanant des établissements d'enseignement et de recherche français ou étrangers, des laboratoires publics ou privés. 


\title{
In-situ experimental and numerical studies of the damage evolution and fracture in a $\mathrm{Fe}-\mathrm{TiB}_{2}$ composite
}

\author{
Z. Hadjem-Hamouche ${ }^{a, *}$, K. Derrien ${ }^{a}$, E. Héripréb, J.-P. Chevalier ${ }^{a}$ \\ ${ }^{a}$ PIMM, Arts et Métiers-ParisTech/CNAM/CNRS UMR 8006, 151 bd de l'Hôpital, Paris, France \\ ${ }^{\mathrm{b}}$ Laboratoire de Mécanique des Solides, UMR 7649, CNRS, École Polytechnique, Palaiseau, France
}

\section{A R T I C L E IN F O}

\section{Keywords:}

Metal matrix composite $\mathrm{Fe}-\mathrm{TiB}_{2}$

Damage

In-situ

DIC

$\mathrm{AE}$

FFT

Homogenization

\begin{abstract}
A B S T R A C T
A joint experimental and modelling study of plastic strain and ensuing damage in a novel metal matrix composite $\left(\mathrm{Fe}-\mathrm{TiB}_{2}\right)$ is presented. Damage is observed and quantified using SEM images processing and Acoustic Emission (AE) analysis. The use of AE confirms that the surface damage observed is strongly correlated to damage in the bulk of the material. The primary mode of damage is particle fracture. Very little particle decohesion is observed, indicating an exceptionally good cohesion of the steel/particle interface. Damage is initiated soon after the composite yield point is reached and increases significantly with strain. Macroscopic failure of the tensile specimen occurs when about $25 \%$ of the particles are fractured. This corresponds to about $21 \%$ engineering strain.

Using in-situ SEM tensile tests with quantitative digital image correlation (DIC), full-field strain measurements are obtained and particle fracture quantified. The results of fields measurements are compared to results of a FFT based homogenization method with boundary conditions retrieved from the experiment. A good agreement is found between the DIC-measured and FFT-predicted results. Estimated values of the particle fracture stress are obtained.
\end{abstract}

\section{Introduction}

Lightweight structures for transportation have become a major area of development for improved energy efficiency and decreased $\mathrm{CO}_{2}$ emissions. A solution is to develop taylored materials with improved specific properties. Novel steel-based composites reinforced with titanium diboride particles have been developed by ArcelorMittal in this context. This material consists of a significant volume fraction $(\sim 13 \%)$ of titanium diboride $\left(\mathrm{TiB}_{2}\right)$ particles dispersed in a ferritic steel matrix. It is obtained during solidification directly from the melt through a near eutectic solidification route $[1,2]$. The phase diagram indicates that, depending on composition, the $\mathrm{TiB}_{2}$ phase will precipitate in the melt (primary particles) and the eutectic $\mathrm{TiB}_{2}$ phase be formed by the eutectic reaction. This leads to a relatively homogeneous distribution of particles, with little clustering, and since the particles are formed in situ, strong interfacial bonding. These should both favour good mechanical properties and resistance to damage [3].

These composite steels were designed for high stiffness associated with low density. This is achieved by selecting a high modulus low density particulate phase, so as to obtain a maximum value for the specific stiffness $(\mathrm{E} / \mathrm{\rho})$. It was also necessary that these steels be produced on an industrial scale using a process such as continuous casting.
Therefore, the steel composition had to present a eutectic in the phase diagram, in order to obtain the composite microstructure directly on solidification. With these criteria defined, the choice centered on titanium diboride $\left(\mathrm{TiB}_{2}\right)$, with a very high Young's modulus (583 $\mathrm{GPa}$ ) and a low density $\left(\rho=4.52 \mathrm{~g} / \mathrm{cm}^{3}\right.$ ). The Fe-TiB ${ }_{2}$ composite (with $13 \% \mathrm{TiB}_{2}$ particles) yields a value of Young's modulus of $240 \mathrm{GPa}$ for a density of $7.39 \mathrm{~g} \mathrm{~cm}^{-3}$, which corresponds to a significant increase in specific stiffness $(>15 \%)$ [1]. Furthermore, the low solubility of $\mathrm{Fe}$ in $\mathrm{TiB}_{2}$ $\left(<4\right.$ at\%) suggests that the high value of $\mathrm{E}$ for $\mathrm{TiB}_{2}$ will not be strongly changed by any dissolved Fe.

This composite is thus very promising for components with stiffness as the design criterion. However, both plastic deformation, ensuing damage and fracture behavior are not fully understood. So far, two studies deal with mechanical and damage behavior of this $\mathrm{Fe}-\mathrm{TiB}_{2}$ composites $[4,5]$. The first was focused on the damage evolution of $\mathrm{Fe}-\mathrm{TiB}_{2}$ composites during bending test and the second on the effect of simple shearing up to large plastic strain on damage evolution. Here, we focus on understanding plastic deformation of a $\mathrm{Fe}^{-\mathrm{TiB}_{2}}$ composite leading to damage and the relation to the composite microstructure.

Strain at the macro-scale is usually considered as homogenous, while heterogeneous strains occur at the micro-scale level due to the variation in mechanical properties of the constituents. Detection and

\footnotetext{
* Corresponding author.

E-mail address: zehoua.hamouche@ensam.eu (Z. Hadjem-Hamouche).
} 
measurement of local microstructural strain plays a key role for damage analysis and may provide guidelines for microstructure optimization. One method allowing the full field strain at the microstructural scale to be obtained is digital image correlation (DIC) combined with in-situ tensile testing [6-9]. Nevertheless, the validity of observations made on a free surface to describe damage and strain processes occurring within the bulk of a material $[10,11]$ may be questioned. The simultaneous use of acoustic emission (AE) allows the monitoring of the damage evolution on the whole volume of the specimen during tensile tests to be monitored. AE is a non-destructive method that is widely used in studying damage [12-14]. It has been used to study the mechanical behavior of various types of composites under tensile loading $[12,14-19]$. Several mechanisms are proposed as the source of acoustic emissions $[14,20]$ during the strain and failure of particle reinforced MMCs. These include fracture of particles, debonding of interfaces (known as void nucleation), and void coalescence (matrix relaxation).

In recent years, micromechanical models based on the microstructure of multi-phase materials have been developed. Among the different strategies for improving the efficiency of the calculations based on the finite elements method, full-field calculations based on Fast Fourier Transforms (FFT) have proved to be a serious alternative for periodic inhomogeneous materials. The FFT-based homogenization was originally proposed by Moulinec and Suquet [21]. Both the equations governing the mechanical behavior of heterogeneous materials with periodic microstructures and the strategy for solving these equations using FFT techniques are presented in several papers [22,23]. FFTbased homogenization has been used to investigate the behavior of different types of heterogeneous materials and behavior [24-29]. In this paper, the FFT based approach is used to investigate the plastic behavior and damage of the metallic matrix composite $\mathrm{Fe}-\mathrm{TiB}_{2}$.

The present work, based on an experimental and numerical approach, is focused on using the combination of DIC and AE to understand the damage and fracture behavior of $\mathrm{Fe}^{-\mathrm{TiB}_{2}}$, considering this as a "model" metal matrix composite with a simple matrix (ferrite) and a single particulate phase, hence simplifying the analysis of the acoustic response during strain. The experimental measurements are compared with numerical results from the FFT model.

\section{Experimental and FFT model details}

\subsection{Material and microstructure}

The steel matrix composite studied here was provided by ArcelorMittal Research S.A., Maizières-les-Metz, France. It was prepared by melting scrap iron in an alumina crucible in an induction furnace. The molten steel was deoxidised by the addition of aluminum in order to reduce the oxygen content below $20 \mathrm{ppm}$. Ferro-boron (Fe$20 \% \mathrm{~B}$ ) and ferro-titanium (Fe-70\%Ti) are used to adjust the desired boron and titanium content and the casting temperature is $1400{ }^{\circ} \mathrm{C}$. The steel is cast in a metallic mold of dimension $300 \times 300 \times 1800 \mathrm{~mm}$. In situ precipitation of the $\mathrm{TiB}_{2}$ particles occurs during solidification by eutectic reactions $[1,2]$. The as-cast steel is reheated to $1200^{\circ} \mathrm{C}$ before hot rolling to $3 \mathrm{~mm}$ thickness, with a final rolling temperature of $900{ }^{\circ} \mathrm{C}$. This is followed by air cooling and then coiling at $600^{\circ} \mathrm{C}$. The hot rolling is thus carried out in the austenitic phase and the austenite-ferrite transformation occurs during the subsequent cooling.

The Fe-Ti-B steel studied here is hypereutectic (see Table 1 for the composition). The solidification begins with the formation of primary $\mathrm{TiB}_{2}$ particles followed by heterogeneous nucleation of $\delta$ iron dendrites.

Table 1

Chemical composition of the $\mathrm{Fe}-\mathrm{TiB}_{2}$ composite.

\begin{tabular}{lllllllllll}
\hline Element & C & Al & Cr & Mn & Ni & Si & Ti & B & P & Fe \\
\hline wt $\%$ & 0.04 & 0.07 & 0.06 & 0.09 & 0.04 & 0.17 & 5.4 & 2.11 & 0.01 & Bal.
\end{tabular}

The eutectic reaction transforms the liquid in $\delta$ iron and $\mathrm{TiB}_{2}$ and occurs during cooling to $1250{ }^{\circ} \mathrm{C}$. At this temperature, the austenite phase is formed by a peritectic reaction. Solidification is completed with the disappearance of the liquid phase [30]. The primary $\mathrm{TiB}_{2}$ particles develop basal and prismatic planes as interfacial planes with bcc $\delta$ iron.

For the composite studied, the volume fraction of $\mathrm{TiB}_{2}$ particles is about $13 \%$. The microstructure was characterized from longitudinal (parallel to the rolling direction) (TD, LD), transversal (TD, ND) and normal (LD, ND) plane sections by SEM-EBSD. The microstructure obtained consists of primary $\mathrm{TiB}_{2}$ crystals surrounded by a eutectic mixture of ferrite and $\mathrm{TiB}_{2}$ particles (Fig. 1, $\mathrm{TiB}_{2}$ particles appear with dark contrast). The particles are uniformly distributed in the matrix. The characterization from (LD, TD) shows the presence of two types of particles: large primary particles with a mean size of $11,4 \mu \mathrm{m}$ which exhibit mainly hexagonal or prismatic sections, and small eutectic particles with sharp corners, various shapes and a mean size of 1,6 $\mu \mathrm{m}$. The particles having a size less than or equal to $5 \mu \mathrm{m}$ represent approximately $91 \%$ of particles of the material (Fig. 1) but represent approximately $1 \%$ of the total volume fraction. The c-axis of the particles tend to be aligned with the rolling direction leading to the distribution in Fig. 1(c).

The crystal structure of the $\mathrm{TiB}_{2}$ particles was determined by X-ray powder diffraction analysis from extracted particles and was found to be hexagonal [1], as expected. Most particles are elongated along the caxis, which is parallel to the rolling direction (Fig. 1(a)). Recent atomic scale studies of interfaces by high resolution electron microscopy $[31,32]$ show that the primary particles are at least partially coherent.

Furthermore, these results show that the $\mathrm{TiB}_{2}(0001)$ basal plane is covered by a TiC layer three atomic planes thick. The steel is hot rolled in the austenitic phase and the $\mathrm{TiC}$ precipitation occurs during the austenite to ferrite transformation and further cooling [31]. The composite contains $0.04 \mathrm{wt} \%(0.2 \mathrm{at} \%)$ of carbon distributed between the $\mathrm{TiB}_{2}$ particles and the ferritic matrix. Carbon, as well as titanium, are in solid solution in austenite and then entirely engaged in TiC precipitation during cooling. The volume fraction of TiC must be lower than $0.35 \%$ in the $\mathrm{Fe}-\mathrm{TiB}_{2}$ composite as some carbon is present in the $\mathrm{TiB}_{2}$ particles [32]. The carbon level is not critical since the interfacial TiC phase does not seem to reduce the interfacial strength.

EBSD maps of crystal orientations on $1 \times 1 \mathrm{~mm}^{2}$ surfaces revealed that the matrix exhibits equiaxed grains in the rolling direction (TD-LD) plane with a mean grain size of $10 \mu \mathrm{m}$ (Fig. 2). A weak crystallographic texture is observed in the matrix.

\subsection{In situ SEM tensile testing}

$5 \mathrm{~mm}$-wide, $1 \mathrm{~mm}$-thick tensile specimens with a gauge length of $20 \mathrm{~mm}$ were machined parallel to the rolling direction (RD) from the hot rolled composite (Fig. 3). The samples were mechanically polished, involving specific diamond grinding discs (diamond size down to $1 \mu \mathrm{m}$ ) and commercial colloidal silica suspension (abrasive particles size $0.25 \mu \mathrm{m}$ ). A gold micro-grid with a pitch of $2 \mu \mathrm{m}$ was printed over a $500 \times 500 \mu \mathrm{m}^{2}$ area on the previously polished surface, using electron beam lithography [33] (Fig. 3).

Displacement-controlled tensile tests were performed on a testing machine with a maximum load capacity of $5 \mathrm{kN}$, in a FEI QUANTA 600F scanning electron microscope. During the tests, conducted up to fracture, the axial strain was measured using an extensometer (gauge length $14 \mathrm{~mm}$ ) attached to the sample. The strain rate was $5 \cdot 10^{-3} \mathrm{~s}^{-1}$. A typical stress-strain curve recorded during tension is given in Fig. 4. The tests were interrupted at pre-determined stress (strain) levels and the specimens remained under load during the capture of high resolution images ( $4096 \times 3536$ pixels). The present experiment work can be divided into two parts. First, the initial damage rate and its evolution during in-situ SEM tensile tests, combined with the acoustic emission technique, are determined. Secondly, the strain fields by digital image correlation using the CMV software [34] are measured. Three in situ- 


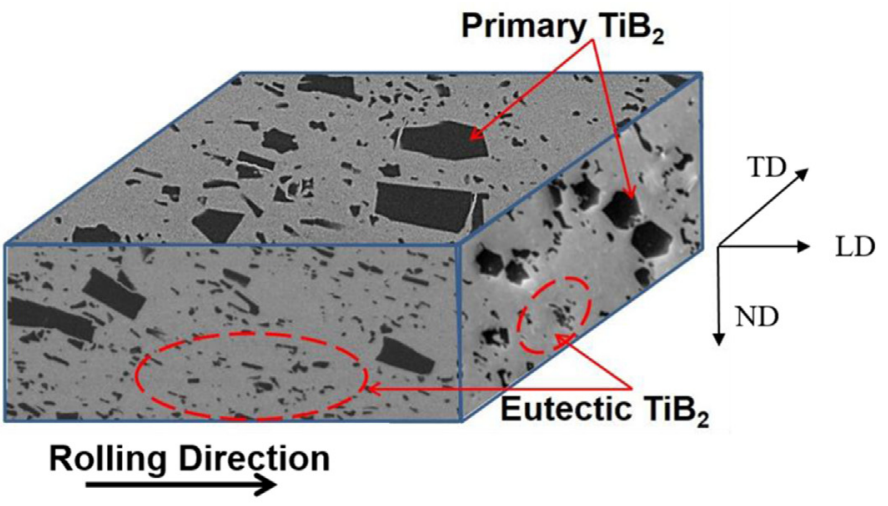

(a)
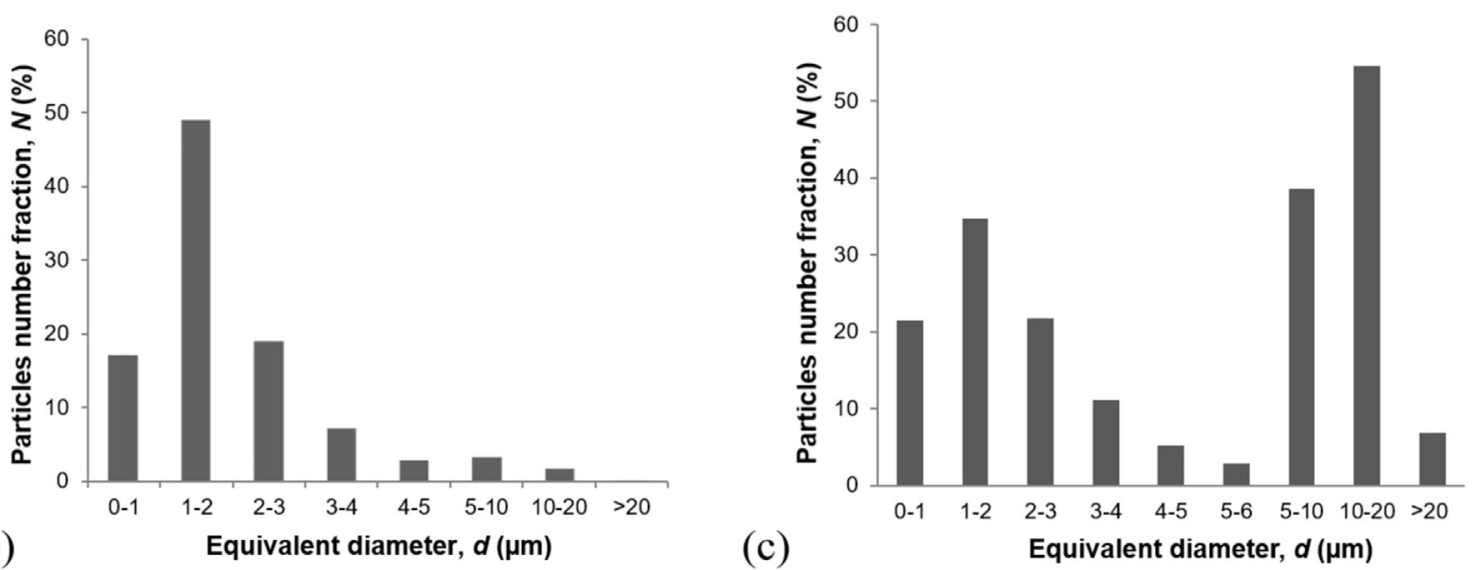

Fig. 1. (a) Backscattered SEM micrographs showing the distribution of TiB2 particulates in iron matrix. The primary and eutectic TiB2 are identified. Overall particle size distribution on (b) (TD, ND) and (c) (TD, LD) sections.

tensile tests, combined with the acoustic emission, were conducted and the curves are shown in Fig. 10.

\subsection{Acoustic emission (AE) analysis}

$\mathrm{AE}$ signals were recorded during the in situ tensile tests using two wide band sensors (frequencies ranging between $100 \mathrm{kHz}$ and $400 \mathrm{kHz}$ ). The exact sensor position on the surface of the tensile specimen is shown in Fig. 3. Silicon grease used as an acoustic coupling to improve the signal transmission between specimens and sensor. AE signals were recorded with a sampling rate of $1 \mathrm{MHz}$ and their thresholds were set at $45 \mathrm{~dB}$ to filter noise. From the AE waveform, characteristic parameters of the $\mathrm{AE}$ signal can be extracted, such as its amplitude, duration, count number, rise time, and energy.

\subsection{A multi-scale approach for the determination of the composite's} effective properties

Determination of the effective properties of the composite is a solid mechanics problem which can be solved using mean-field approaches based on Eshelby's inclusion theory using the properties of the constituent phases. These approaches make use of analytical approximation like the self-constituent scheme [35] or the Mori-Tanaka model $[36,37]$. The approaches are restricted to simple microstructures which are uniformly distributed in term of their size or volume fraction for example. The stress in the inclusion is assumed to be constant in all inclusions. This may be an important limitation for the simulation of particles failure.

On the other hand, full field simulations allow the effect of size, volume density or local stress and strain fields to be taken into account. We use here a numerical FFT method based on a solution of a unit cell problem with periodic boundary conditions. The unit cell under
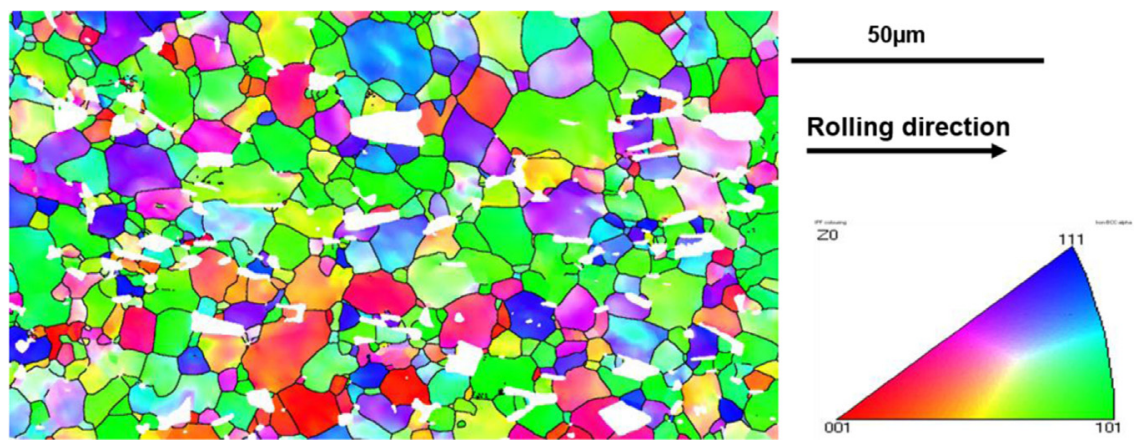

Fig. 2. EBSD mappings of grain orientations in the rolling direction (TD-LD) plane. 


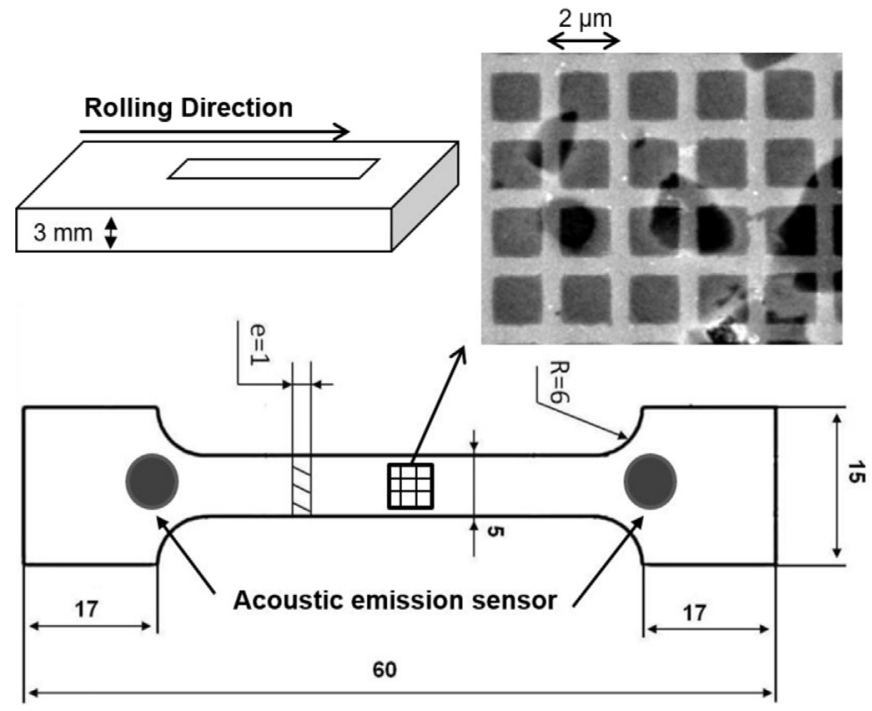

Fig. 3. Geometry of the tensile specimen and location of the gold micro-grids and the AE-sensor.

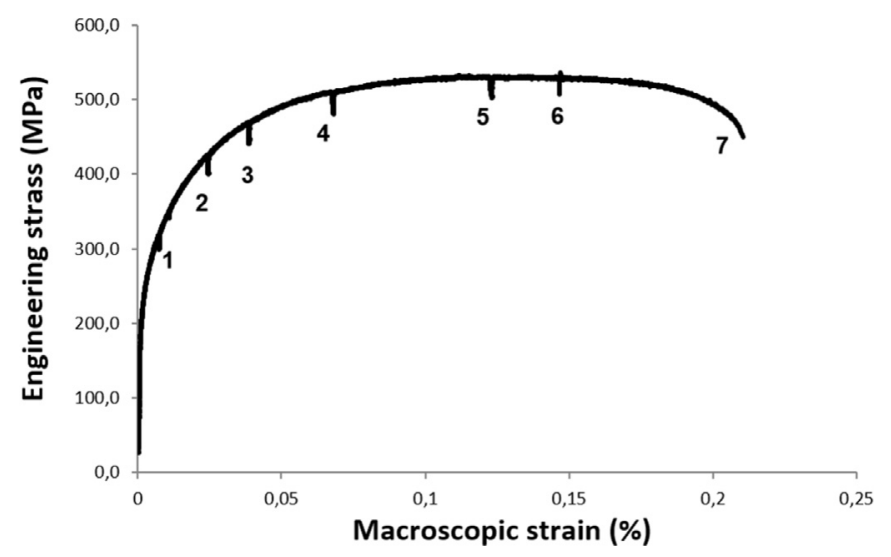

Fig. 4. Stress-strain curve recorded during in situ tensile testing in the SEM. 1-7 indicate the strain steps where the load is maintained and images recorded.

consideration is discretised into N1 * N2*N3 Fourier points. This discretisation produces a regular grid in the Cartesian space and a corresponding grid in the Fourier space. The definition of a linear reference medium is also required. The Fourier transform of the Green operator associated with the reference medium can be obtained for each point of the Fourier grid. The FFT-based algorithm then consists in finding a strain-rate field, associated with a cinematically admissible velocity field, that minimizes the average of the local strain energies, under the constraint imposed by the strain compatibility condition.

An iterative scheme must be implemented to obtain, upon convergence, a compatible strain rate field and a stress field in equilibrium. This method provides the exact solution for a given microstructure, with details on stress and strain fields, but at the cost of some numerical effort.

For the composite studied here, the volume fraction of $\mathrm{TiB}_{2}$ particles is around $13 \%$, corresponding to approximately $12 \%$ of large primary particles and $1 \%$ of eutectic particles. To represent these two types of particles, a multi-scale approach is used. The contribution of eutectic particles to the behavior of the composite is taken into account by analytically determining the behavior of a new equivalent matrix composed of a ferritic matrix with small eutectic particles. For this, the Mori-Tanaka's model is used: the $\mathrm{TiB}_{2}$ particles were assumed to be elastic, isotropic and with a Young's modulus and a Poisson ratio of: $E_{T i B_{2}}=583 \mathrm{GPa}, \nu_{T i B_{2}}=0,11$. The ferritic matrix is isotropic,

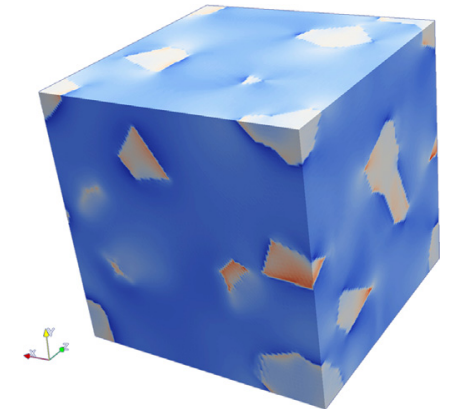

Fig. 5. Periodic representative volume element used for the different FFT calculations. The volume element is discretized into $128 \times 128 \times 128$ voxels.

characterized by a Young's modulus of $E_{F e}=206 \mathrm{GPa}$ and a Poisson ratio of $\nu_{F e}=0,29$, and an elastic-plastic law:

$\varepsilon_{e q}=\frac{1}{n-1} \frac{\sigma_{S}-\sigma_{0}}{H_{0}}\left(\left(\frac{\sigma_{S}-\sigma_{0}}{\sigma_{S}-\sigma_{e q}}\right)^{n-1}-1\right)$

With: $\varepsilon_{e q}$ being the equivalent strain in the matrix (Von Mises strain), $\sigma_{e q}$ the equivalent stress in the matrix (Von Mises stress). The material parameters $H_{0}, n, \sigma_{S}$ and $\sigma_{0}$ were those of [38]; $\sigma_{0}=260 \mathrm{MPa}, \quad n=5, \quad \sigma_{s}=1030 \mathrm{MPa}, H_{0}=5750 \mathrm{MPa}$.

The application of the Mori-Tanaka model to approximate the behavior of the ferritic matrix with $1 \%$ of eutectic particles yields the following values:

$E_{\mathrm{Fe}}=208 \mathrm{GPa}, \quad \nu_{\mathrm{TiB}_{2}}=0,29$.

The yield stress is $\sigma_{0}=262 \mathrm{MPa}$ and the plastic law of this eutectic phase is tabulated. This is then implemented in the FFT calculations.

In order to represent the $\mathrm{Fe}-\mathrm{TiB}_{2}$ composite, the volume element presented in Fig. 5 is used. The microstructures considered here are periodic three-dimensional unit-cells randomly generated by Voronoi tesselation. The Voronoï mosaic is considered as a two-phase material, a continuous ferritic matrix (equivalent matrix composed of a ferritic matrix with small eutectic particles) and particles of $\mathrm{TiB}_{2}$. The $\mathrm{TiB}_{2}$ primary particles are randomly distributed in the ferritic matrix. The volume element consists of 200 equiaxed matrix grains with random crystallographic orientations and includes $20 \mathrm{TiB}_{2}$ particles. For the application of the FFT-based resolution method, the unit cell or volume element under consideration is discretized into $128 \times 128 \times 128$ Fourier points. The FFT calculations were carried out using the CRAFT software provided by Moulinec and Suquet [21].

In the composite studied, the average primary particles size is about $11 \mu \mathrm{m}$, but varies between 5 and $30 \mu \mathrm{m}$. In order to take in consideration particle distributions similar to those observed, we chose to vary the microstructure generation parameters. We have randomly generated 50 microstructures. We then chose 10 microstructures, for a total of 200 varying size particles. The choice was made in order to better reproduce the observed size distribution with a volume fraction of $12 \%$. Fig. 6 allows the comparison between the measured size distribution obtained by image analysis and the FFT simulated distribution of the primary $\mathrm{TiB}_{2}$ particles. For the FFT calculations, only the primary particles embedded in this eutectic matrix are taken into account.

\section{Experimental and numerical results}

\subsection{Damage evolution}

The evaluation of damage in the Fe-TiB2 composite was carried out through an analysis of the SEM micrographs. Locations of particle fracture and particle/matrix decohesion were detected on the micrographs for each loading step. Prior to loading, the surface is free of any identifiable damage (Fig. 7). The main damage initiation mechanism 


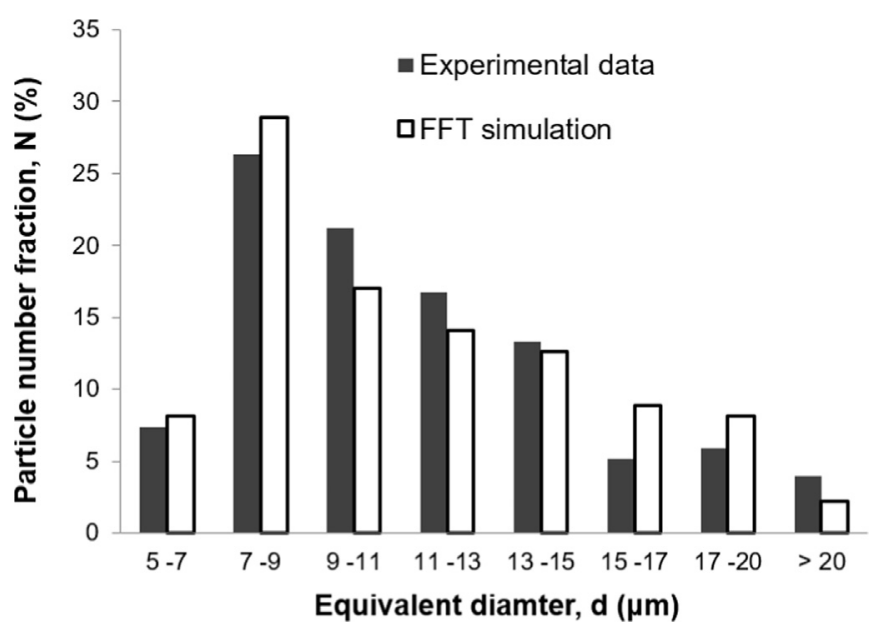

Fig. 6. Comparison between the measured size distribution obtained by image analysis and the FFT simulated distribution of the primary $\mathrm{TiB}_{2}$ particles.

corresponds to fracture of the primary $\mathrm{TiB}_{2}$ particles (compare Figs. 7 and 8). The first particle fractures (Fig. 8(a)) are observed in the composite material for an average macroscopic plastic true strain of the sample $\varepsilon_{\mathrm{p}}=0.5 \%$ and an applied true stress $\sigma_{\mathrm{a}}=320 \mathrm{MPa}$ (higher than the yield stress for the composite, $\sigma_{0.2}=270 \mathrm{MPa}$ ). Most of the time, the cracks occur perpendicularly to the loading axis, indicating that the particles are fractured due to local tensile stress in the particle. Subsequently, increasing plastic strain, resulting from small increases in stress, results in a strong increase in the fraction of fractured particles. Furthermore, the majority of primary particles exhibits multiple cracks (Fig. 8). This means that the mechanical load transfers between the matrix and the particles still operates, even after the first cracks. Some energy can thus remain stored in the particle after the first fracture. This particle multi-cracking process has already been observed by Gammage et al. [39].

The width of the initial cracks in the particles also increases with the plastic strain, so the crack-tips ahead of fractured particles are blunted and the crack propagation is retarded (compare the images in Fig. 8). This can occur because the stress field in front of the crack tip is high. Therefore, dislocations are emitted in directions inclined at an angle roughly equal to $45^{\circ}$ to the crack plane, leading to very strong local shear strain bands in the matrix (see Fig. 8). Owing to the stress concentration induced by the crack tip in these particles directions, these bands are intragranular (Fig. 9).

During the last strain stages, neighboring cracks coalesce through the appearance of secondary cracks inside the matrix and this leads to the final fracture of the sample. Particle-matrix interface decohesion is also observed, but this occurs less frequently and generally at higher values of plastic strain. These observations support the conclusion that particle fracture occurs much more frequently than interfacial decohesion, indicating that interfacial strength is not the limiting factor in damage accumulation for these specific composites.

Generally, the stress state is triaxial in the sample volume and plane on the free surfaces. The particles fracture stress is then reached earlier on the surface than at the bulk. The fracture surface study showed that the number of damage initiation sites is different (less particles are fractured) in the bulk of the material, but the observed mechanisms are similar.

After the in-situ tensile tests (either complete or interrupted), the specimens were polished to reduce surface effects and quantitative SEM image analysis allowed the main features of particles damage to be identified. This enabled the determination of the fractured particle volume fraction, representative of the bulk material and the SEM observations are made on representative areas of the deformed samples.

\subsection{Acoustic Emission (AE) analysis during tensile testing}

In addition to the SEM examination of the specimens, acoustic emission analysis (AE) in combination with quasi-static tensile testing was used. The aim is to provide a clear identification of the failure mechanisms and especially the damage evolution in the bulk until final failure. The relation between the AE signal (cumulative number of hits) and one of the stress-strain curves is shown in Fig. 10. This shows that the first hits occurred at the beginning of the plastic strain and this is consistent with the microscopic observations of primary particles damage at the surface (Fig. 8). The number of AE hits increases considerably with plastic strain, indicating the occurrence of significant damage in the material. The events recorded at the transducer are from individual failure processes and include particles undergoing multiple failures. Since multiple cracking occurs, the number of events recorded corresponds to the number of cracks and not the number of damaged particles.

The measured hits provide information on the macroscopic behavior and damage of the composite, and the good correlation with the SEM observations means that the observed surface damage is a reliable indicator of the damage in the volume of the material. (a)

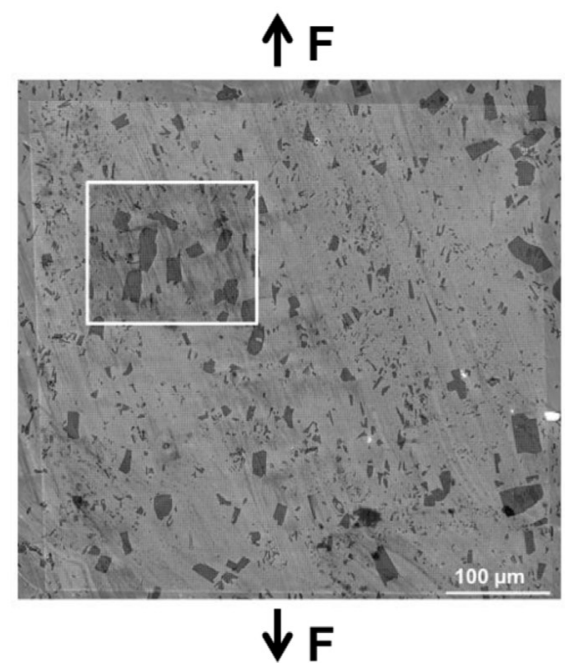

(b)

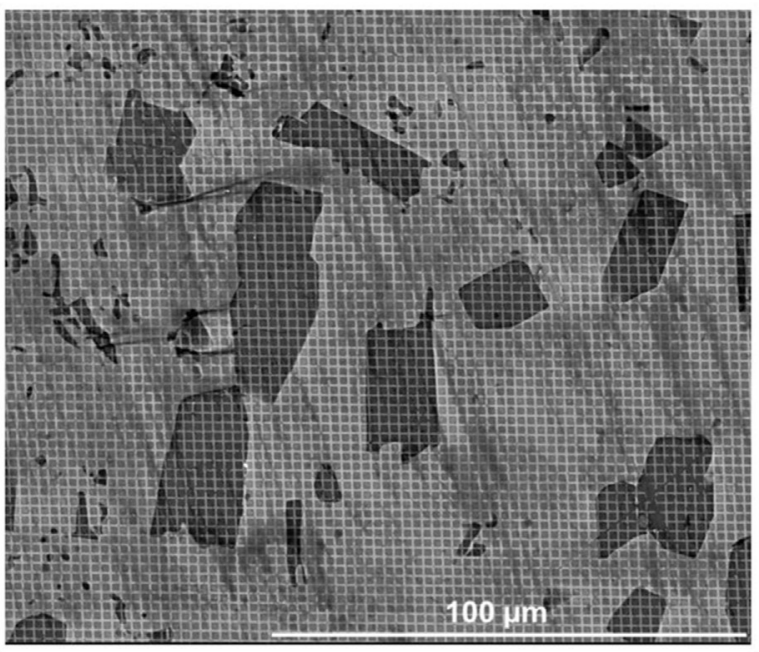

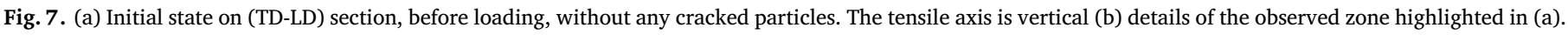
Note the presence of the gold microgrid as a network of white lines. 
(a)

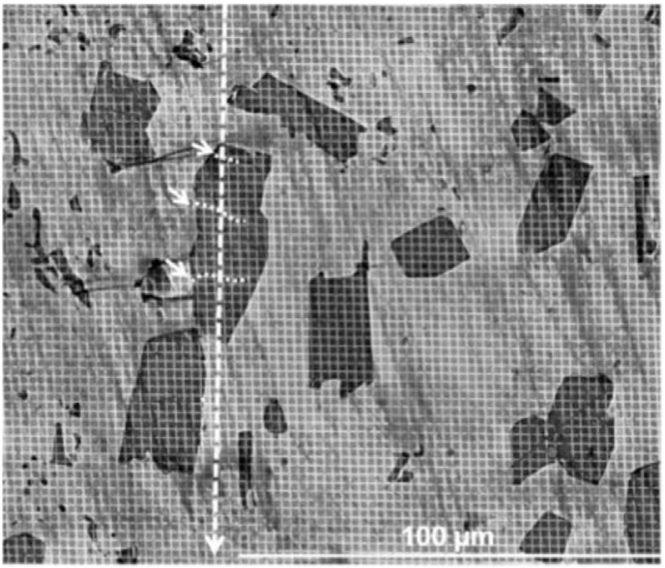

(c)

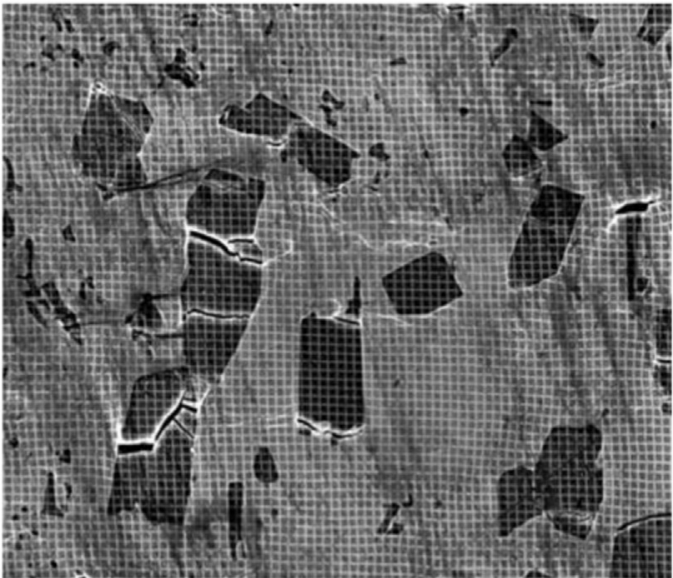

(b)

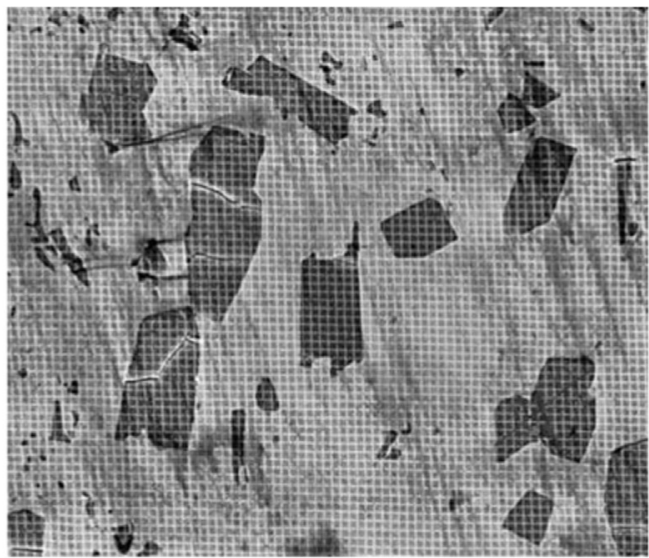

(d)

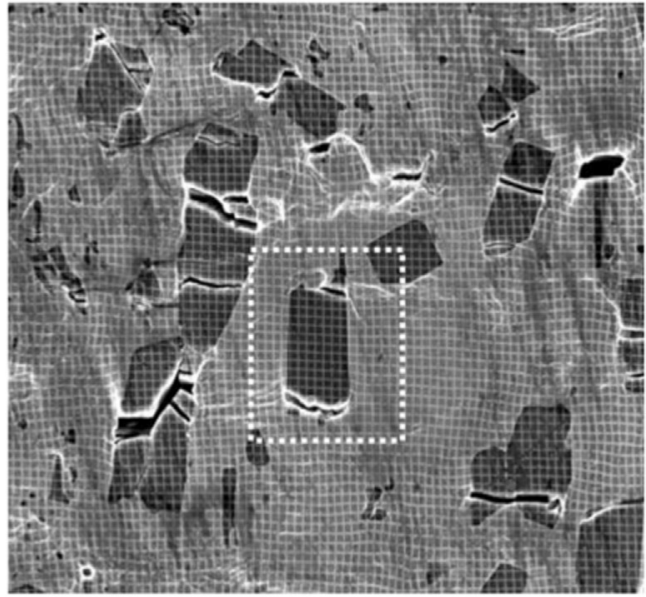

(e)

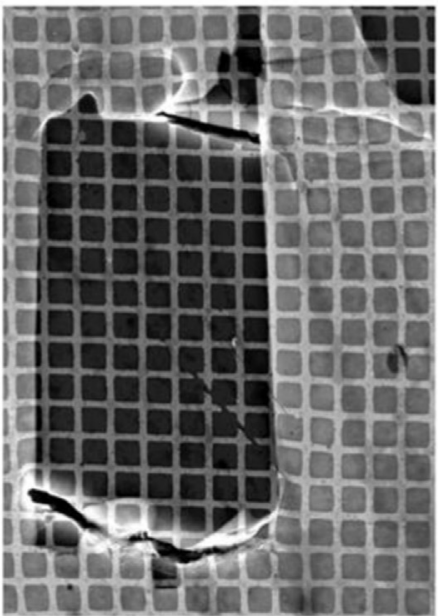

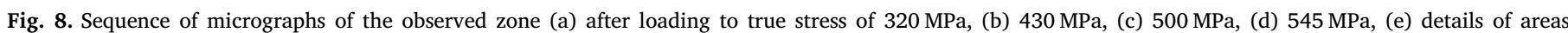
highlighted in (d), no particle debonding is observed. Note the strain of the microgrid near the particle crack.

\subsection{Microstructural strain distribution (strain field)}

Fig. 7 shows the undeformed reference image after gold microgrid deposition. This image was used for the digital image correlation (DIC) analysis by means of the CMV software. The gold microgrids do not mask the microstructure which enables the correlation of the measured DIC strains with the microstructure.

The DIC equivalent Von Mises plastic strain fields $\left(\varepsilon_{\mathrm{VM}}\right)$, at the overall true stresses of $430 \mathrm{MPa}$ and $500 \mathrm{MPa}$ (after the yield point) are shown in Fig. 11. The loading direction is vertical in the images presented in this study. In these figures, different colors indicate different values of $\varepsilon_{\mathrm{VM}}$. It can be seen from the maps that the strain is not homogeneous but concentrates in an array of rather straight shear bands that form at an angle of about $45^{\circ}$ to the loading axis (Fig. 11(a) and (b)). Such band structures are strongly influenced by the non-deformable $\mathrm{TiB}_{2}$ particles. The paths taken by the bands is determined by the arrangement of primary $\mathrm{TiB}_{2}$ particles in the matrix; they form where they find long free paths in the matrix. Often, they proceed close to $\mathrm{TiB}_{2}$ particles. The evolution of the strain heterogeneity at a magnified region (showed in Fig. 7(b)) is presented in Fig. 11(c) and (d). From this series of strain maps, it can be seen that changes in the magnitude of strain heterogeneities occur whereas the spatial location 
(a)

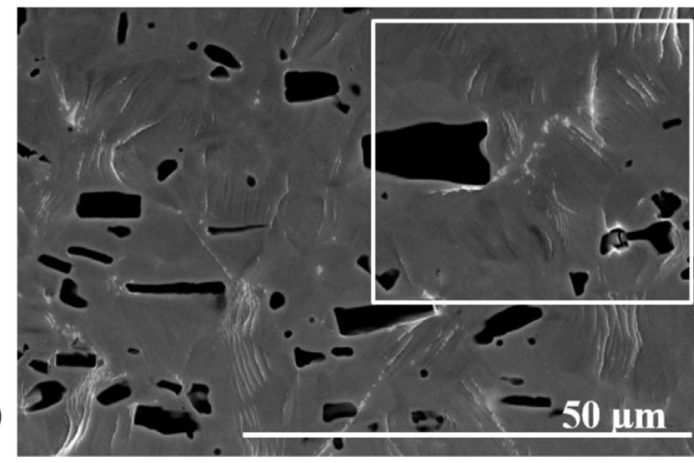

(b)

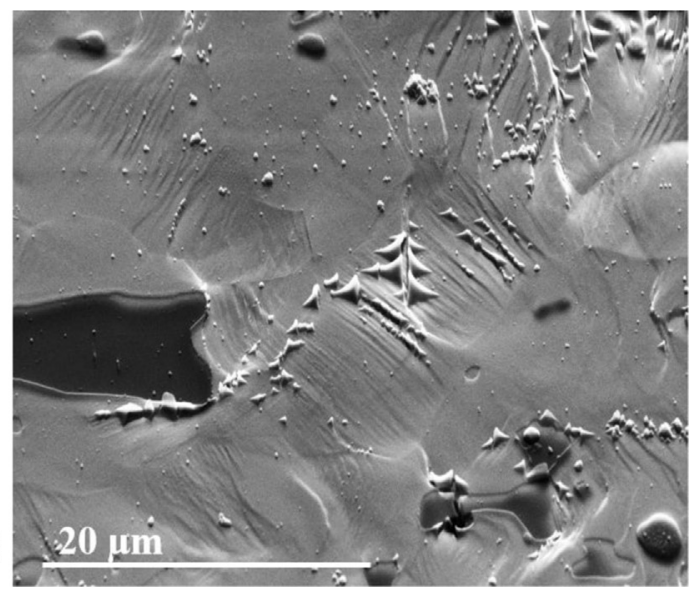

Fig. 9. (a) Plastic strain in matrix, (b) details of areas highlighted in (a).

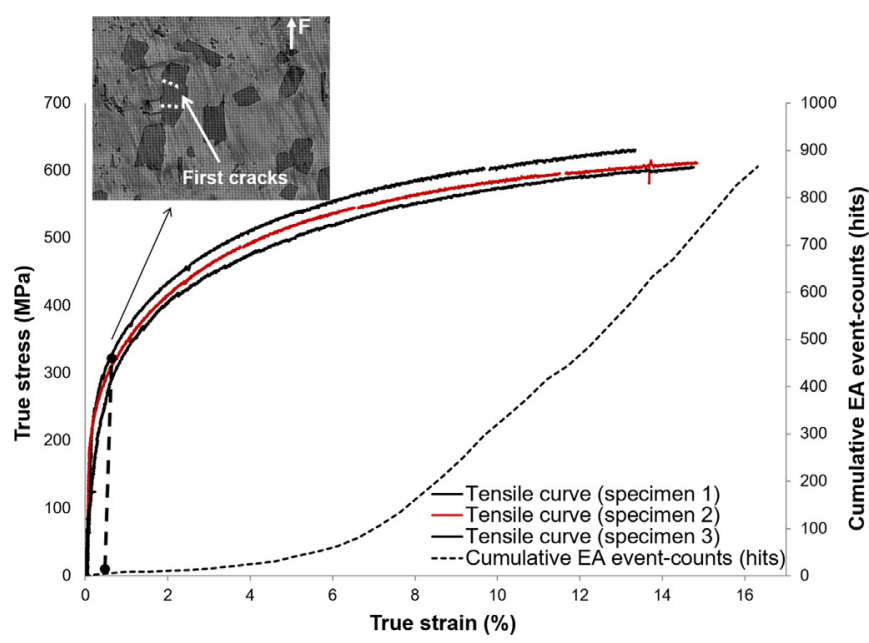

Fig. 10. In-situ stress-strain curves for three different specimens. The AE cumulative EA event counts corresponds to the red tensile curve.

of these heterogeneities are relatively stable during straining.

In order to visualise the strain variations, a vertical line was randomly selected on the micrograph (see Figs. 8(a) and 11(d)). As shown in Fig. 12, the equivalent Von Mises strain values increase to a maximum by reaching the center of a shear band and then decrease by further distance from the shear bands. It can be seen that the strain bands form early and that the widths of the bands do not change with increasing stress. The locations of three particles are shown in the interval between the two vertical dotted lines in Fig. 12. The peaks 1, 2 and 3 correspond to the cracks in primary $\mathrm{TiB}_{2}$ particle. Due to the large difference in mechanical properties between the particles and the matrix, the strain values change abruptly when crossing the particle/matrix interface and this phenomenon leads to difficulties for the strain evaluation in the interface region.

The local strain in the loading direction $\left(\varepsilon_{11}\right)$, was also measured in the particles (Fig. 13). This requires that points on the boundary of the particle are excluded because their strain is calculated in part by points in the matrix. The correlation was performed on a regular scheme based on the grid junctions, taking into account the displacements of the 8 nearest points. Thus, only the primary particles can be considered, since the secondary particle size corresponds to only one or two squares in the grid and the strain fields cannot be measured. The strain at the onset of particle fracture in the regions analysed was estimated and hence the fracture stress can be obtained, assuming that the particles are perfectly elastic. It should be noted that this value, denominated as $\sigma_{F r}$ Part , is only an approximate value, since damage evolution was detected only at the different load steps. Moreover, it will be clear that the fracture of brittle particles will follow Weibull statistics.

The average $\mathrm{TiB}_{2}$ fracture stress is estimated at about $1400 \mathrm{MPa}$. This value is of the same order as previous results [38,40], where the particle failure stress was estimated as being between 900 and $1400 \pm 50 \mathrm{MPa}$, as a function of particle size, on the basis of experimental results and a damage model for heterogeneous materials.

\subsection{FFT results}

The results are obtained by taking an ensemble average over all configurations. The error associated with the averaging procedure is evaluated and the process is repeated until the effective properties are known within a given confidence interval. The number of simulations is considered sufficient if this error is less than one per cent. The stressstrain curves predicted by simulation are shown in Fig. 14. The curve corresponds to the mean response, i.e. the average of the stress-strain curves over the 10 configurations. This Figure shows that the FFT computation overestimates the stress reached in the composite at about $5 \%$ strain. This is due to the damage in the composite material, characterized by the primary particles fracture (see Fig. 8), and which is not taken into account in the numerical simulation. As mentioned previously, damage increases with the macroscopic plastic strain of the sample. The AE cumulative hits curve (Fig. 14) exhibits three distinct damage zones for the composite considered, under quasi-static tensile test. AE cumulative hits initiate directly after the onset of the first damage and the curve advances with a slope closely equal to zero up to damage progression at about $2 \%$ of strain (damage initiation stage). Then, a moderate increment in the AE response is accentuated by the evolution of macroscopic damage modes until about $5 \%$ of strain (damage propagation stage) before a steep increase in the slope of the cumulative curve which can be observed up to fracture (unstable damage growth stage).

The $\mathrm{TiB}_{2}$ particle fracture occurs according to the crack opening mode. The cracks are perpendicular to the maximum principal stress. The mean principal stress in the particles is represented as a function of the macroscopic strain in Fig. 15. At 5\% of macroscopic strain, where significant increase in the damage fraction was observed, the mean stress in all the particles is close to $1100 \mathrm{MPa}$. This mean stress can be considered as the particle fracture stress. This value is in reasonable agreement with that obtained experimentally by images correlation. The Fig. 15 shows that, for a level of macroscopic strain, there is a dispersion of the stresses reached in the particles. The standard deviation on the average stress varies from $100 \mathrm{MPa}$ at $5 \%$ macroscopic strain to reach $200 \mathrm{MPa}$ at $20 \%$ macroscopic strain. However, FFT calculations show that this dispersion of the stress level reached in the particles is not correlated with their size. 
(a)

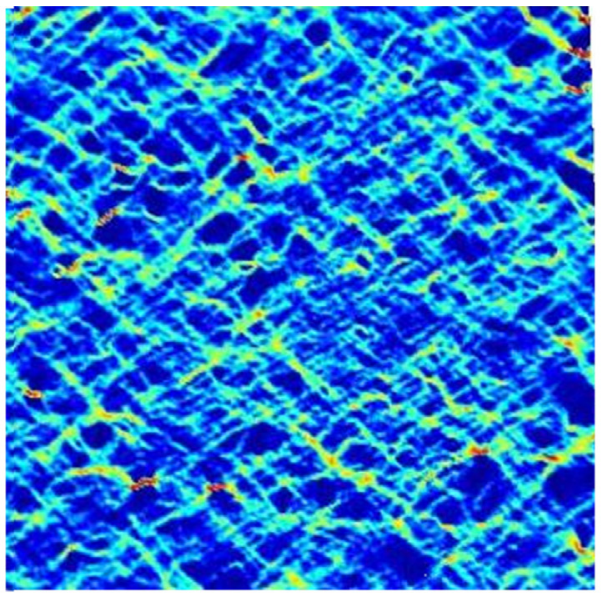

(c)

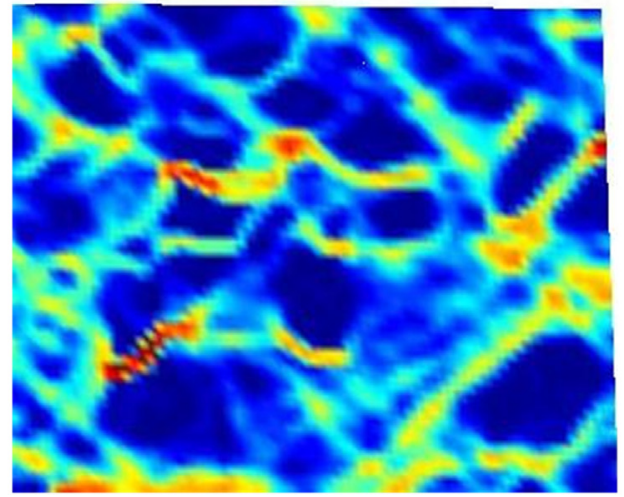

(b)

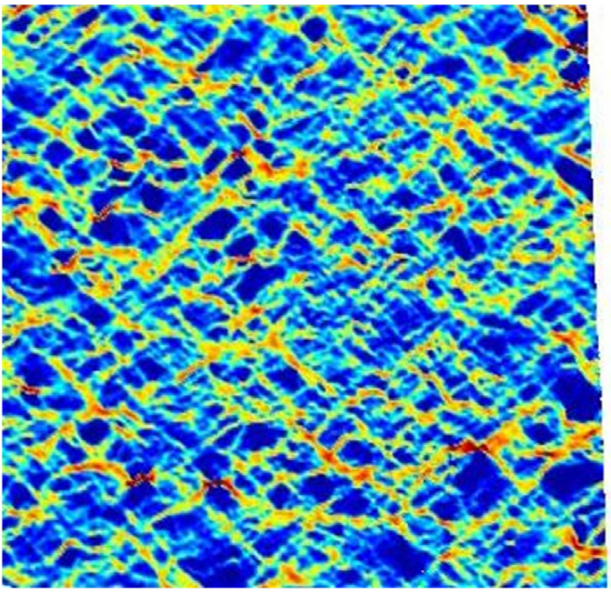

(d)

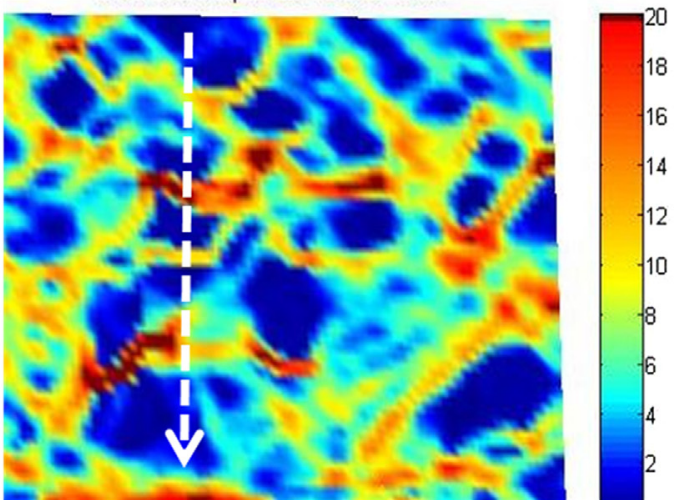

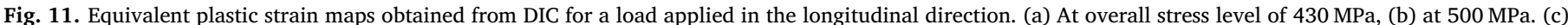

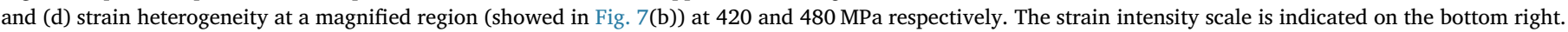

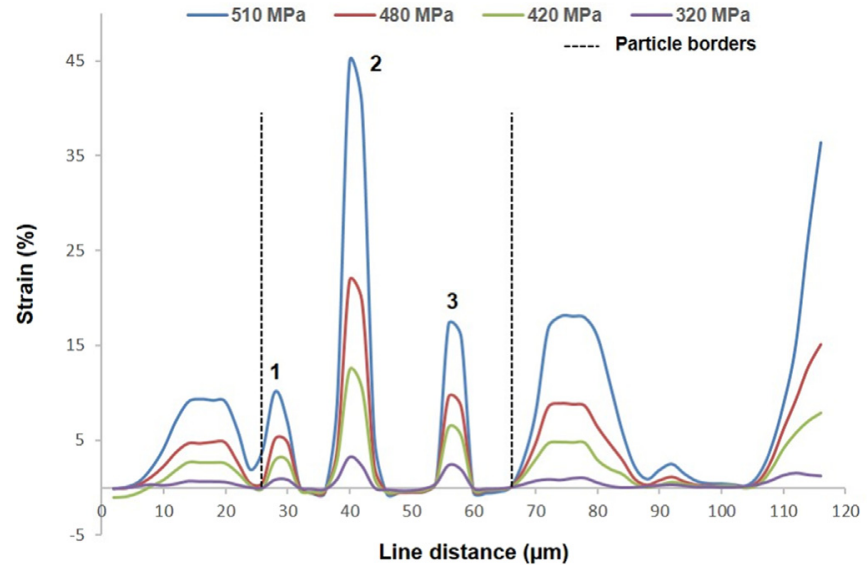

Fig. 12. Equivalent Von Mises strain distribution across the vertical line illustrated in Figs. 8(a) and 11(d).

The maximum principal stress $\sigma_{p}$ applied in every particle was determined for a uniaxial tensile stress applied in the composite. The Fig. 16 represent the evolution of $\frac{\sigma_{p}}{\left\langle\sigma_{p}\right\rangle_{p}}$ as a function of the equivalent diameter of the particles. The results have been plotted for two levels of macroscopic stress, $\sigma_{\text {macroscopic }}=119 \mathrm{MPa}(0.06 \%$ of strain $)$, which corresponds to an elastic stress only and $\sigma_{\text {macroscopic }}=675 \mathrm{MPa}(17 \%$ of strain $)$, for which the composite is then plastically deformed.

The observed stress values dispersion is not correlated to the particle size. This dispersion tends to increase with increasing stress and plastic deformation. This is due to the fact that the local strain in the matrix becomes progressively heterogeneous as the plastic strain increases. This effect is also visible on the Fig. 15 where the measured standard deviation on all simulations is shown.

The experimental observations showed that not all particles were cracked for a given macroscopic stress (strain) level and that the coarse primary particles were prematurely fractured, and in greater number. However, if the stress level reached in the particles is independent of their size (Fig. 16), the size of the particles will still affect their fracture probability for a given stress. In fact, the experimentally observed size effect is characteristic of brittle particles and is essentially due to the probability of finding faults in the particles and this increases with volume. The stress value dispersion associated with the size effect can explain that the fraction of the fractured particles increases continually with macroscopic strain as showed by acoustic emission measurements (Fig. 17).

The size effect can be taken into consideration using a Weibull type statistical law, where:

$\sigma_{p}$ is the main principal stress sustained by the particle

$\mathrm{Pr}$ is the probability for the particle of volume $\mathrm{V}$ to fracture as a result of the stress $\sigma$.

$\operatorname{Pr}=1-\exp \left(-\frac{V}{V_{0}}\left(\frac{\sigma_{p}-\sigma_{s}}{\sigma_{u}}\right)^{m}\right)$

and:

$V_{0}$ is the average particle volume,

$\mathrm{V}$ is the particle volume,

$\sigma_{s}$ is the stress limit below which the particle does not fracture,

$\sigma_{u}$ is the stress for which we observe a $63 \%$ fracture probability, for a 
(a)

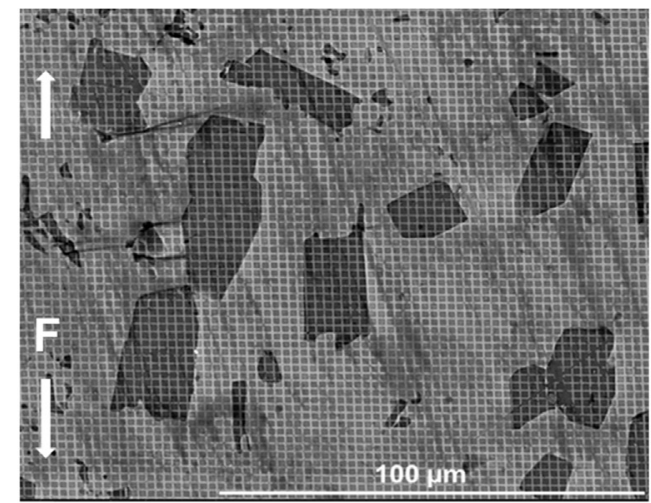

(b)

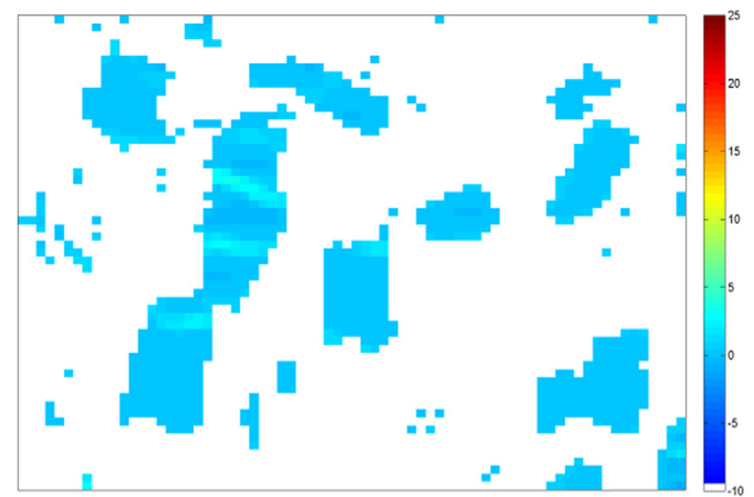

(c)

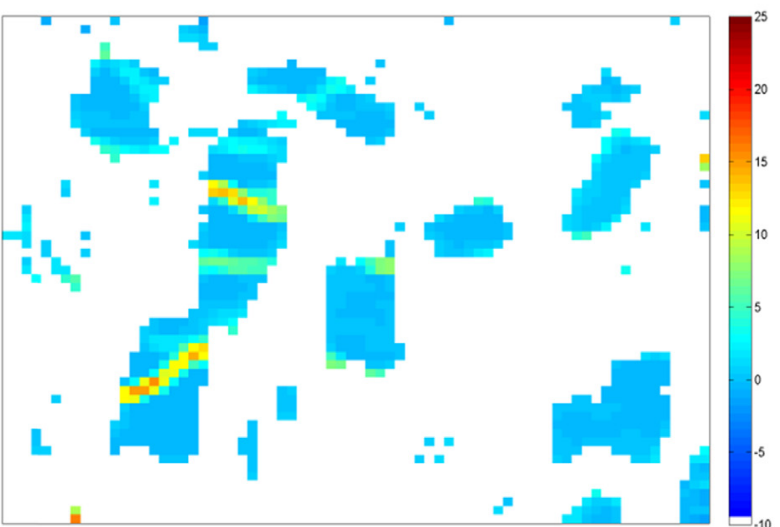

(d)

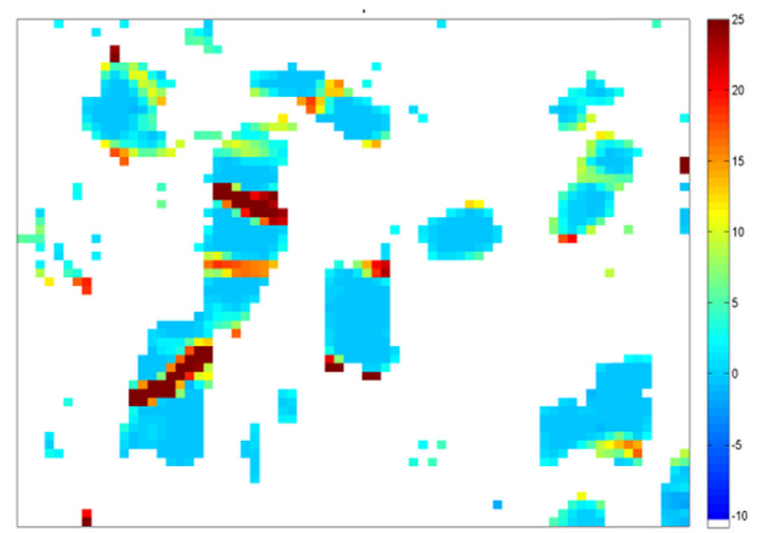

Fig. 13. Longitudinal strain maps $\left(\varepsilon_{11}\right)$ obtained from DIC. (a) Interesting zone before test, (b) at overall stress level of $320 \mathrm{MPa}$, (c) at $430 \mathrm{MPa}$, (d) at $500 \mathrm{MPa}$.

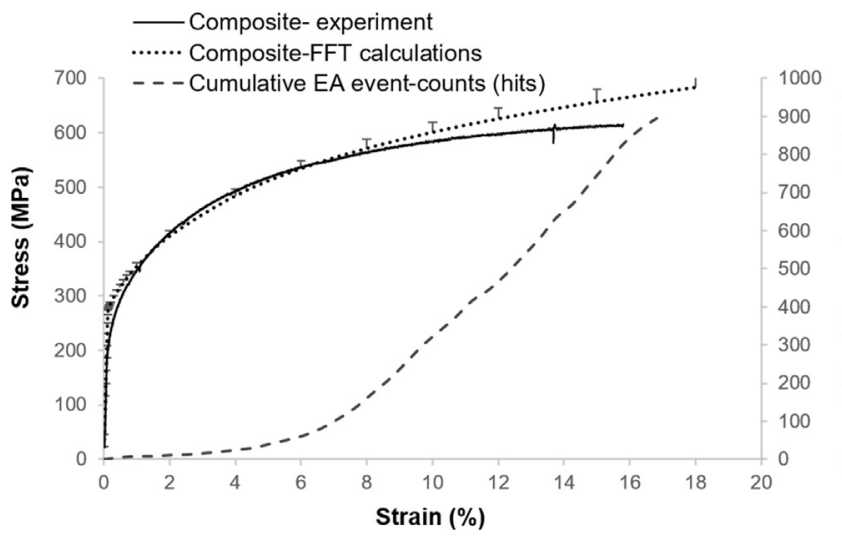

Fig. 14. Correlation between the stress-strain curves evaluated for $13 \%$ volume fraction of $\mathrm{TiB}_{2}$ particles in composite and $\mathrm{AE}$ cumulative number of hits vs strain.

particle volume of $V_{0}$.

The Weibull modulus $\mathrm{m}$ is a material parameter that is characteristic of the dispersion of defects, and hence sensitivity to fracture. The dispersion increases with the decrease of the parameter $\mathrm{m}$. The representative parameters of this law can be identified by analyzing the experimental results.

The Weibull relation has been used to compute the accumulation of fractured particles as a function of the composite macroscopic strain (Fig. 17). In order to identify the Weibull parameter $\mathrm{m}$, the experimental value of the percentage of fractured particles at $15 \%$ macroscopic strain has been chosen as reference. A set of parameters is then adjusted in order to fit this value and the calculated damage evolution is compared to the experimental observations. For high values of $\mathrm{m}$,

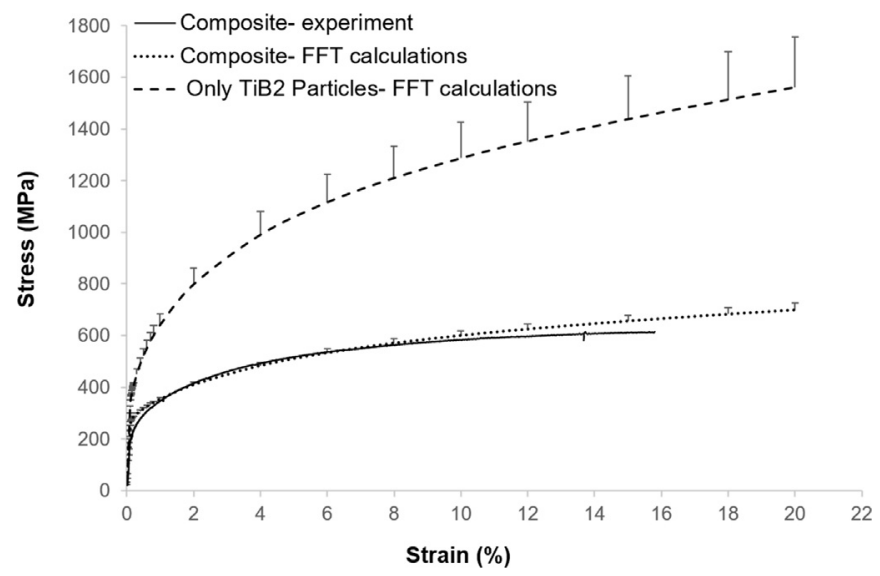

Fig. 15. Stress-strain curves evaluated for $13 \%$ volume fraction of TiB2 particles, in composite and particles.

damage remains very low as a function of deformation, but then increases strongly up to fracture. For low values of $\mathrm{m}$, a high number of particles fracture even for low levels of macroscopic deformation.

The Weibull law parameters, that correspond best to the experimental results, were identified as:

$m=8, \quad \sigma_{s}=300 \mathrm{MPa}, \quad \sigma_{u}=1700 \mathrm{MPa}$.

For this calculation, our microstructure was re-initiated as a function of the damage by replacing fractured particles by elastic particles having the same elastic modulus as the eutectic matrix. The approach is approximate and is likely to overestimate the damage effect on the global behavior of the composite. It can, nevertheless, be considered to give an acceptable first estimation. An ongoing study aims to improve this predicted behavior by integrating the cracks in the particles in the 

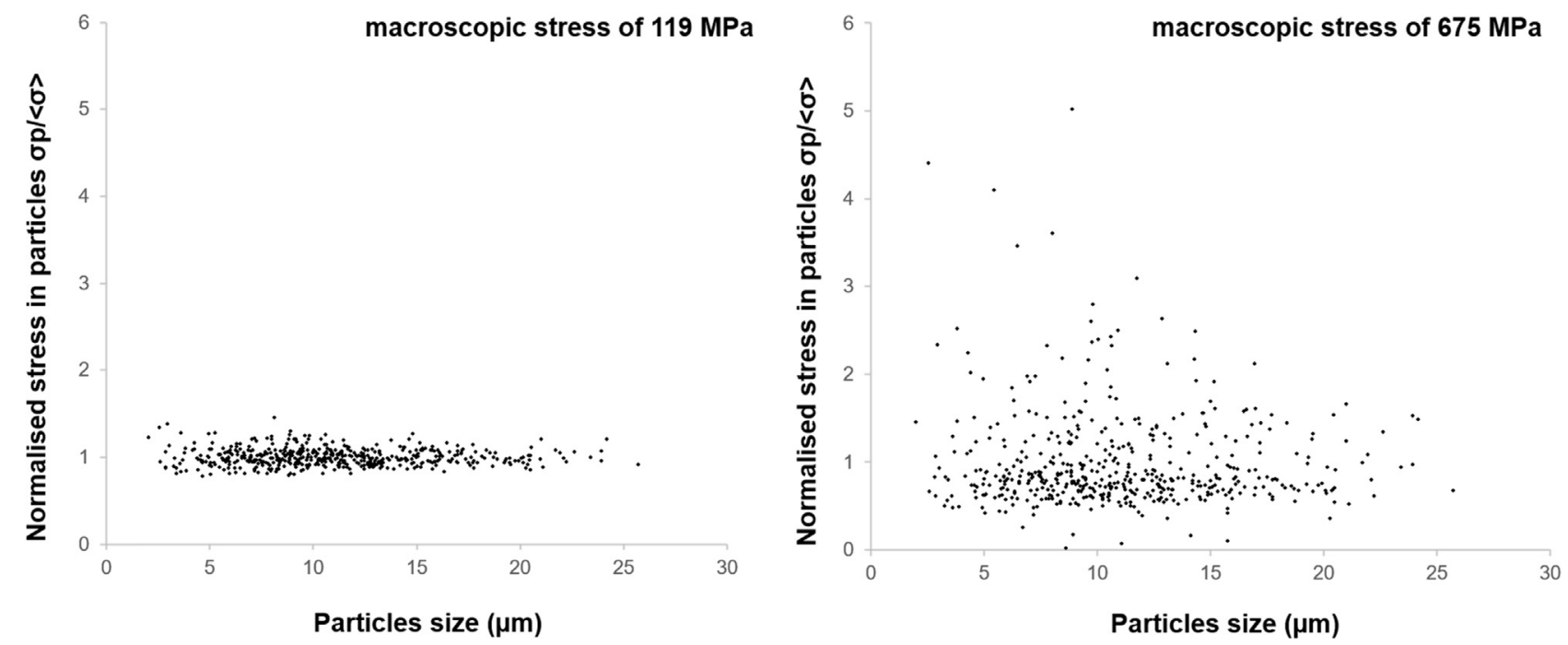

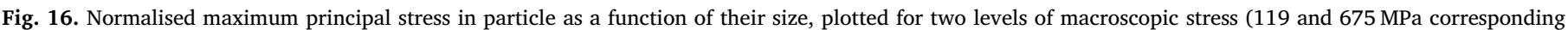
respectively to $0.06 \%$ and $17 \%$ of strain).

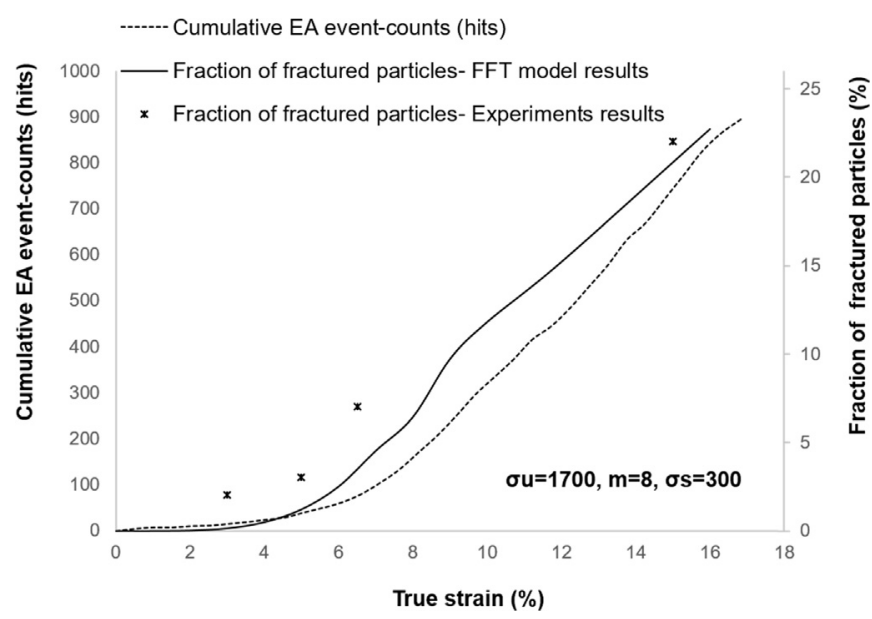

Fig. 17. Cumulative fraction of fractured particles, correlation FFT - experiment results.

computation.

\section{Discussion}

\subsection{Damage behavior}

The results indicate, given the high ductility of the ferritic matrix, that particle fracture is the main reason for tensile failure of the $\mathrm{Fe}-\mathrm{TiB}_{2}$ composite at room temperature. Even though few cracks exist near the interfaces, interfacial strength is not the limiting factor in damage accumulation in these composites. This result is consistent with previous $[4,5]$ studies stating that $\mathrm{Fe}-\mathrm{TiB}_{2}$ composites damage during bending and simple shearing, respectively, by particle fracture. On this basis, continuous casting $\mathrm{Fe}^{-} \mathrm{TiB}_{2}$ composites show an excellent interfacial behavior for transferring stress from matrix to reinforcements, whatever the particle orientation with respect to the load axis. They are able to accommodate the concentrated stress at the crack tip by a blunting mode which retards the coalescence of cracks effectively. The high strength of the particle/matrix interface is supported by the recent work of $[31,32]$ carried on the interface structure and chemistry of these materials and which revealed, due to HRTEM observations, a "clean" $\mathrm{Fe} / \mathrm{TiB}_{2}$ interface with a continuity of atomic planes occurring on each part of the interface thus conferring to the composite a very good interfacial cohesion.

Furthermore, crack initiation is found to occur at a lower stress for the large particle than smaller one. This follows simply from à Weibull analysis, since the FFT results shows that stress levels are independent of particle size. The larger particles are statistically weaker. The fracture mechanism is attributed to the coalescence of cracks initiated in the large particles. Here, controlling the particle will be important in order to optimize the mechanical behavior, particularly in improving ductility and toughness.

The qualitative analysis of damage and strain processes described in this paper is based on the observations made on a free surface. The use of acoustic emissions (EA) allows to complete these results with data on the damage evolution in the volume of the specimen during tensile tests. The EA results confirm that the primary particles damage occurred at the beginning of the plastic strain and the observed surface damage is strongly correlated to damage in the bulk of the material. The fracture surface study showed that the number of damage initiation sites is different (less particles are fractured) in the bulk of the material, but the observed mechanisms are similar.

The fracture of the particles causes several acoustic emission events with a large amount of energy. Given that the $\mathrm{TiB}_{2}$ particles undergo multiple fractures, the number of events recorded should correspond to the number of cracks and not the number of damaged particles. This particle multi-cracking can be explained by the fact that some energy can remain stored in the particle after it is fractured by the first crack. The shock wave induced by the first crack could increase the defect probability in the remaining particle. The nucleation of a second crack could then be facilitated. This particle multi-cracking process has already been observed by Gammage et al. [39]. These authors developed a simple analytical model of the multi-cracking.

\subsection{Local microstructural strain}

\subsubsection{Accuracy of the measurements}

It should be noted that the resolution of the computed strains is affected by the pitch size of the microgrid which should be compatible with the material microstructure. This is the key parameter for the image discretisation and therefore directly influences the strain estimation [41]. Here, the pitch size is less than the matrix grain and the primary $\mathrm{TiB}_{2}$ particle size. The best correlation results were obtained for the pitch used.

The error on the strain depends on the type of discrete derivation scheme used for the calculation and the number of pixels between each 
correlation point [33]. An integration scheme that takes into account a large number of neighboring measurement points leads to a more accurate strain. In this case, the measured value corresponds to the average over a larger area than with a more localized integration scheme with less neighboring points. In this study, a discrete derivation scheme taking into account the displacements of the 8 nearest points is used to access accurate strain values.

During the in-situ SEM tensile tests, high resolution images were captured using a slow scanning rate at about $20 \mathrm{~min}$ per image. This long time involves distortion of the digital image due to scanning inaccuracies. These are taken into account when evaluating the strain field by image correlation and included in the background noise measurement [34]. In this study, the reliability of the results was, for example, tested by calculating strains after a simple translation of the microgrid. The evaluation of the technique accuracy is not the purpose of this paper. However, it is worth noting that the value of the lowest strain that can be reliably detected should be larger than 0.01 .

\subsubsection{Local strain and strain mechanisms}

The strain fields were measured in 2-dimensions. This is a shortcoming of the DIC measurement. In reality, subsurface microstructural features affect the strain fields on the surface i.e. a $\mathrm{TiB}_{2}$ particle located below the surface may induce higher strain on the surface. Such an effect was captured by the DIC. Moreover, during the tensile strain, fracture and/or decohesion of particles occur along the applied load direction. Such particle fracture is captured as a displacement in the DIC program and influences the local strain values. Consequently, the influence of the subsurface microstructure together with particle fracture caused different locations of the maximum strain in the matrix measured by DIC.

The present DIC method treats the interface in the same way as anywhere else. It means that a subimage at the interface contains both phases. This treatment usually underestimates the strain in the matrix and overestimates the strain in the particle. One of the possible solutions to reduce this interface effect is to reduce the pitch of the microgrid. The evaluation of the strain at the interface can be improved by dividing the subimage located at the interface into two phases corresponding to the particle and the matrix. So, two deformation values could be calculated for the two phases separately. This separation was not carried out in this work. Consequently, the strain at the particle/ matrix interface could not be evaluated, but it can be seen in Fig. 11(c) and (d) that the plastic strain at the interface is small compared to that in the matrix.

As the metal deforms elastically and then plastically, the $\mathrm{TiB}_{2}$ particles were stressed elastically and when the tensile stress reaches the fracture stress, $\sigma_{\text {Fr Part }}$, transverse cracks develop. The strain behavior of the interface in this material is not clear yet, though it is crucial for the overall mechanical properties. In addition to the effect of the interfacial structure and chemistry, the behavior of dislocations and their interactions near the interface should be taken into account in order to provide insight into the mechanical strain processes that occur in the vicinity of metal-particle interfaces.

Interfacial plasticity after nanoindentation tests has been studied by transmission electron microscopy (TEM) [42]. It shows that the interfaces between $\mathrm{TiB}_{2}$ particles and ferrite matrix can be subjected to large plastic strain, with increased dislocation densities, before debonding occurs. The interaction between the dislocations and the interface would be influenced by the applied stress, image forces, interface forces and forces due to any residual thermal stress. Studies on the dislocation pile-ups at the interface have shown that in addition to the image forces that may repel dislocations, forces due to the short-range stress of the misfit dislocations at the interface may also prevent strain related dislocations from reaching the interface [43,44]. Gustafson et al. [45] have explained the plastic flow behavior in the $\mathrm{Al}-\mathrm{MgAl}_{2} \mathrm{O}_{4}$ composite in terms of a mechanism where the leading dislocation in a pile-up has to overcome the repulsion force from the low angle grain boundary for sustained strain. The plastic strain in this composite is accompanied by the development of low angle sub-boundaries in aluminum. These low angle boundaries are a result of slip compatibility forced by the stress at the metal-ceramic interface [46]. Slip compatibility means that strain in the slip planes in the metal ligaments must be accommodated by crystal slip parallel to the interface.

With respect to the strain mechanism in the $\mathrm{Fe}^{-\mathrm{TiB}_{2}}$ composites, it can be suggested that dislocations propagate at or near the interface. The accumulation of these dislocations could then promote the nucleation of microcracks. At present, the roles played by dislocations in the fracture of the ceramic particles and in the mechanical response of the metal matrix near metal-ceramic interfaces are still questions to be answered.

\section{Conclusions}

The main features of damage evolution and fracture in a $\mathrm{Fe}-\mathrm{TiB}_{2}$ metal matrix composite, as a function of the strain were established using three methods; SEM image quantitative analysis, EA analysis and FFT calculations. The cumulated fraction of damaged particles was found to increase with the macroscopic plastic strain of the sample. Experimentally, an average volume fraction of fractured particles of approximately $25 \%$ is observed, just before the specimen fracture. The proportion of fractured particles near to the fracture surface is much higher, but not representative of the performed computations. Acoustic emission allows the damage threshold to be detected and to show a linear increase of the percentage of fractured particles with increasing stress.

Two aspects should be stressed, i.e. the methodology and the results concerning the material. The methodology implemented here, due to the association of EA measurements with in situ SEM tensile tests, clearly shows the damage can be robustly monitored from SEM (surface) micrographs, as a function of strain. This is confirmed by ex situ polishing of the tensile specimens to gain information on particle cracking in the volume. A very good correlation between particle cracking and the EA signal is observed. DIC of the micrographs yields quantitative values of local strain and demonstrates the strongly inhomogeneous plastic deformation in this material. The FFT methodology used introduces the key microstructural features and the calculations reproduce satisfactorily the experimental tensile curves. Furthermore, it allows quantification of the stress in the particles to be obtained as well as the fraction of cracked particles. The methodology used here can now be considered as a robust means of studying quantitatively inhomogeneous plastic deformation and ensuing damage.

The results confirm previous findings on the $\mathrm{Fe}-\mathrm{TiB}_{2}$ metal matrix composite, but also provide new insight. The effect of the exceptionally high interface cohesion is confirmed: particle fracture is the overwhelming damage mechanism and decohesion is only rarely observed. These results indicate that interfacial strength is not the limiting factor in damage accumulation and fracture in this composite. The previously identified damage process has now been quantified (damage occurs at the onset of plasticity and specimen fracture occurs when about $25 \%$ of the particles are cracked). Quantitative digital image correlation (DIC) allows local full-field strain measurements. The measured fields are compared to results of a FFT based homogenization method with boundary conditions retrieved from the experiment. It has been shown that the stress value in the particles is independent of the particle size (both in the elastic and plastic regimes), and cracking is then related to size through a Weibull law, i.e. the defect probability increases with particle volume. The Weibull parameters have been quantitatively determined through fitting the FFT calculations with the experimental results. Estimated values of the particle fracture stress (1400 MPa from DIC and around $1100 \mathrm{MPa}$ from FFT) have been obtained. Since the larger particles crack first, improvements in the material's process conditions will have to aim at reducing the volume fraction of these large particles in order to delay the onset of damage and improve both 
ductility and toughness. Finally, the FFT methods used now enable "model" microstructures to be introduced and tested. This is a valuable tool in order to define "optimum" microstructures.

\section{Acknowledgments}

The authors would like to thank Dr. Frédéric Bonnet, from ArcelorMittal Research S.A., Maizières-les-Metz, France, for providing the material necessary for this study and for valuable discussions. They also thank Dr. Hervé Moulinec for allowing them to use the CRAFT software.

This work is supported by the Agence Nationale de la Recherche (ANR) through the ADRERA project N_ ANR-09-MAPR-0001.

The ESEM (FEI Quanta 600) used in this work has been acquired with the financial support of Region Île de France (SESAME 2004 program), CNRS and Ecole Polytechnique.

\section{References}

[1] ARCELOR Research Group; Patent EP 1897963 A1, Bulletin 2008/11, 2008, p. 20.

[2] F. Bonnet, V. Daeschler, G. Petitgand, High modulus steels: new requirement of automotive market. How to take up challenge, Can. Metall. Q. 53 (2014) 243-252.

[3] V. Raghavan, B-Fe-Ti (boron-iron-titanium), J. Phase Equilib. 24 (2003) 455-456.

[4] Z. Hadjem-Hamouche, J.-P. Chevalier, Y. Cui, F. Bonnet, Deformation behavior and damage evaluation in a new titanium diboride (TiB2)- steel based composite, Steel Res. Int. 83 (6) (2012) 538-545.

[5] M. Dammak, M. Gaspérini, D. Barbier, Microstructural evolution of iron based metal-matrix composites submitted to simple shear, Mater. Sci. Eng. A 616 (2014) 123-131.

[6] H. Jin, W. Lu, J. Korellis, Micro-scale strain measurement using the digital image correlation technique and scanning electron microscope imaging, J. Strain Anal. Eng. Des. 43 (2008) 719-728.

[7] J.D. Carroll, W. Abuzaid, J. Lambros, H. Sehitoglu, An experimental methodology to relate local strain to microstructural texture, Rev. Sci. Instrum. 81 (2010).

[8] J.D. Carroll, W. Abuzaid, J. Lambros, H. Sehitoglu, High resolution digital image correlation measurements of strain accumulation in fatigue crack growth, Int. J. Fatigue 57 (2013) 140-150.

[9] C.C. Tasan, M. Diehl, D. Yan, C. Zambaldi, P. Shanthraj, F. Roters, D. Raabe, Integrated experimental-simulation analysis of stress and strain partitioning in multiphase alloys, Acta Mater. 81 (2014) 386-400.

[10] P.M. Mummery, B. Derby, in: N. Hansen, D. Juul Jensen, T. Leffers, H. Lilholt, T. Lorentzen, A.S. Pedersen, O.B. Pedersen, B. Ralph (Eds.), Metal Matrix CompositesProcessing, Microstructure and Properties, Riso National Laboratory, Denmark, 1991 , p. 535

[11] F. Lagattu, F. Bridier, P. Villechaise, J. Brillaud, In-plane strain measurements on a microscopic scale by coupling digital image correlation and an in situ SEM technique, Mater. Charact. 56 (1) (2006) 10-18.

[12] A. Rabiei, M. Enoki, T. Kishi, A study on fracture behavior of particle reinforced metal matrix composites by using acoustic emission source characterization, Mater. Sci. Eng. A293 (1-2) (2000) 81-87.

[13] A. Niklas, L. Froyen, M. Wevers, L. Delaey, Acoustic emission during fatigue crack growth in SiC Particle reinforced Al matrix composites, Metall. Mater. Trans. 26A (12) (1995) 3183-3189.

[14] P.M. Mammery, B. Derby, C.B. Scruby, Acoustic emission from particulate-reinforced metal matrix composites, Acta Metall. Mater. 41 (1993) 1431.

[15] S. Barré, M.L. Benzeggagh, On the use of acoustic emission to investigate damage mechanisms in glass-fibre-reinforced polypropylene, Compos. Sci. Technol. 52 (1994) 369-376.

[16] R. El Guerjouma, J.C. Baboux, D. Ducret, N. Godin, P. Guy, S. Huguet, et al., Nondestructive evaluation of damage and failure of fibre reinforced polymer composites using ultrasonic waves and acoustic emission, Adv. Eng. Mater. 3 (2001) 601-608.

[17] E. Maire, V. Carmona, J. Courton, W. Ludwig, Fast X-ray tomography and acoustic emission study of damage in metals during continuous tensile tests, Acta Mater. 55 (20) (2007) 6806-6815.

[18] N. Zarif Karimi, H. Heidary, G. Minak, M. Ahmadi, Effect of the drilling process on the compression behavior of glass/epoxy laminates, Compos. Struct. 98 (2013) $59-68$.

[19] E. Maillet, N. Godina, M. R'Milia, P. Reynauda, G. Fantozzi, J. Lamon, Real-time evaluation of energy attenuation: a novel approach to acoustic emission analysis for damage monitoring of ceramic matrix composites, J. Eur. Ceram. Soc. 34 (2014) 1673-1679.

[20] A. Rabiei, B.N. Kim, M. Enoki, T. Kishi, A new method based on simultaneous acoustic emission and in-situ SEM observation to evaluate the fracture behavior of metal matrix composites, Scr. Mater. 37 (1997) 801-808.

[21] H. Moulinec, P. Suquet, A numerical method for computing the overall response of nonlinear composites with complex microstructure, Comput. Methods Appl. Mech. Eng. 157 (1998) 69-94.

[22] M. Kabel, D. Merkert, M. Schneider, Use of composite voxels in FFT-based homogenization, Comput. Methods Appl. Mech. Eng. 294 (2015) 168-188.

[23] C. Mareau, C. Robert, Different composite voxel methods for the numerical homogenization of heterogeneous inelastic materials with FFT-based techniques, Mech. Mater. 105 (2017) 157-165.

[24] E. Ghossein, M. Levesque, A fully automated numerical tool for a comprehensive validation of homogenization models and its application to spherical particles reinforced composites, Int. J. Solids Struct. 49 (2012) 1387-1398.

[25] V. Vinogradov, G.W. Milton, An accelerated FFT algorithm for thermoelastic and non-linear composites, Int. J. Numer. Methods Eng. 76 (2008) 1678-1695.

[26] B.S. Anglin, R.A. Lebensohn, A.D. Rollett, Validation of a numerical method based on fast Fourier transforms for heterogeneous thermoelastic materials by comparison with analytical solutions, Comput. Mater. Sci. 87 (2014) 209-217.

[27] J.C. Michel, H. Moulinec, P. Suquet, A computational scheme for linear and nonlinear composites with arbitrary phase contrast, Int. J. Numer. Methods Eng. 52 (2001) 139-160.

[28] R.A. Lebensohn, N-site modeling of a 3d viscoplastic polycrystal using fast Fourier transform, Acta Mater. 49 (2001) 2723-2737.

[29] B. Figliuzzi, D. Jeulin, M. Faessel, F. Willot, M. Koishi, N. Kowatari, Modelling the microstructure and the viscoelastic behavior of carbon black filled rubber materials from 3d simulations, Tech. Mech. 36 (2016) 32-56.

[30] A. Antoni-Zdziobek, M. Gospodinova, F. Bonnet, F. Hodaj, Experimental determination of solid-liquid equilibria with reactive components: example of the Fe-Ti-B ternary system, J. Phase Equilib. Diffus. 35 (2014) 701-710.

[31] L. Cha, S. Lartigue-Korinek, M. Walls, L. Mazerolles, Interface structure and chemistry in a novel steel-based composite Fe-TiB2 obtained by eutectic solidification, Acta Mater. 60 (18) (2012) 6382-6389.

[32] S. Lartigue-Korinek, M. Walls, N. Haneche, L. Cha, L. Mazerolles, F. Bonnet, Interfaces and defects in a successfully hot-rolled steel-based composite Fe-TiB2, Acta Mater. 98 (2015) 297-305.

[33] L. Allais, M. Bornert, T. Bretheau, D. Caldemaison, Experimental characterization of the local strain field in a heterogeneous elastoplastic material, Acta Metall. Mater. 42 (1994) 3865-3880.

[34] P. Doumalin, M. Bornert, J. Crépin, Characterisation of the strain distribution in heterogeneous materials, Méc. Ind. 4 (2003) 607-617.

[35] R. Hill, A self-consistent mechanics of composite materials, J. Mech. Phys. Solids 13 (1965) 213-222.

[36] T. Mori, K. Tanaka, Average stress in matrix and average elastic energy of materials with misfitting inclusions, Acta Metall. 21 (1973) 571-574.

[37] Y. Benveniste, Revisiting the generalized self-consistent scheme in composites: clarification of some aspects and a new formulation, J. Mech. Phys. Solids 56 (2008) 2984-3002.

[38] M. Dammak, Evolutions microstructurales, écrouissage et endommagement de composites à matrice métallique $\mathrm{Fe}-\mathrm{TiB}_{2}$ en chargement montone inversé (Ph.D. thesis), Paris 13, 2014.

[39] J.J. Gammage, D.S. Wilkinson, J.D. Embury, E. Maire, Damage studies in heterogeneous aluminium alloys using X-ray tomography, Philos. Mag. 85 (2005) 3191-3206.

[40] M. Gaspérini, M. Dammak, P. Franciosi, Stress estimates for particle damage in Fe$\mathrm{TiB}_{2}$ metal matrix composites from experimental data and simulation, Eur. J. Mech. A/Solids 64 (2017) 85-98.

[41] H. Haddadi, S. Belhabib, Use of rigid-body motion for the investigation and estimation of the measurement errors related to digital image correlation technique, Opt. Lasers Eng. 46 (2) (2008) 185-196.

[42] M.X. Huang, B.B. He, X. Wang, H.L. Yi, Interfacial plasticity of a TiB2-reinforced steel matrix composite fabricated by eutectic solidification, Scr. Mater. 99 (2015) $13-16$.

[43] J. Dundurs, G.P. Sendeckyj, Edge dislocation inside a circular inclusion, J. Appl. Phys. 36 (1965) 3353.

[44] J.P. Hirth, D.M. Barnett, J. Lothe, Stress fields of dislocation arrays at interfaces in bicrystals, Philos. Mag. A40 (1979) 39.

[45] T.W. Gustafson, P.C. Panda, G. Song, R. Raj, Influence of microstructural scale on plastic flow behavior of metal matrix composites, Acta Mater. 45 (4) (1997) $1633-1643$.

[46] Y.C. Lu, S.L. Sass, Deformation processes in the vicinity of metal-ceramic interfaces, Acta Metall. Mater. 43 (1995) 3283. 